\title{
Los que hablan, ¿para quién hablan? Desafíos del trabajo con testimonios en Argentina*
}

\author{
Federico Lorenz ${ }^{* *}$
}

Volvió a preguntarse para quién escribia el Diario. ¿Para

el pasado, para el futuro, para una época imaginaria?

George Orwell, 1984.

\section{Argentina: salir de la dictadura}

¿Qué sucede cuando una sociedad debe confrontar con un pasado vergonzante y éste es el pasado vivido, el propio? Ésta fue la pregunta que, en la Argentina, comenzó a reclamar una respuesta a principios de los años ochenta. La derrota en la guerra de Malvinas (1982), la indignación y el estupor resultantes generaron un clima de demanda de explicaciones por parte de la sociedad. La pérdida de las islas Malvinas y el desprestigio militar abrieron una puerta a través de la cual los ciudadanos comenzaron a asomarse a los aspectos más terribles de la represión ilegal.

Pero un pasado urgente y aberrante reclamaba no sólo el esclarecimiento, sino también la asunción de responsabilidades por parte de miles

* Una primera versión de este texto fue presentada en el Primer Encuentro Internacional de Historia Oral, Historia Oral, Historia Viva, realizado en la Facultad de Letras de Universidad de Porto (Portugal), del 26 al 28 de octubre de 2006.

** Centro de Pedagogías de Anticipación, Universidad Nacional de Luján (Argentina). 
de argentinos que habían convivido con esa realidad aparentemente más allá de toda imaginación durante varios años. Estas demandas, necesariamente, encerraban cuestionamientos a la propia conducta y éstos se transformaron en preguntas que no era fácil ni hacer ni responder. ¿Qué había pasado? ¿Cómo había pasado? y, acaso la más difícil de responder: ¿Por qué había pasado? La dificultad de este último interrogante estaba fundamentalmente dada por el hecho de que responderlo significaba analizar el contexto social que había generado las condiciones para el desarrollo de la violencia insurgente, producido los mecanismos de la barbarie, educado a los represores y acompañado con una pasividad consciente o inconsciente - cuando no aprobado abiertamente - el desarrollo de la represión ilegal.

\section{El show del horror}

El "qué" y el "cómo" estallaron con fuerza en la opinión pública en la segunda mitad de 1982, como una directa consecuencia de la derrota en la guerra de Malvinas. El desprestigio militar alentó a la prensa, que hasta ese momento había exhibido un silencio casi monolítico sobre el tema de las violaciones a los derechos humanos, a comenzar a publicar, en forma creciente, noticias relativas a las actividades de los organismos de derechos humanos. Sobre todo las Madres de Plaza de Mayo, con sus pañuelos y sus marchas circulares cada jueves, se transformaron en el emblema de la lucha contra la impunidad.

En ese nuevo clima, muchos medios también se sintieron alentados a difundir las noticias acerca del horror. En octubre de 1982 se descubrieron tumbas colectivas de "NN". La prensa exhibió macabras fotografías de pilas de huesos y cráneos exhumados por los empleados de los cementerios y, al mismo tiempo, buscó y difundió por primera vez las voces de las víctimas y de sus victimarios. Lo que durante años habían sido - en muchos casos - rumores en voz baja, se materializaban en fotografías horrendas y en los relatos de los testigos. Aparecieron con fuerza, también, las voces de los familiares de los desaparecidos, quienes habían sostenido en solitario las denuncias y reclamos en los años más duros de la represión.

La prensa divulgó hasta la saturación relatos del cautiverio de numerosos argentinos, historias aberrantes de vejaciones y torturas, y testimonios 
de algunos represores que aumentaban el cuadro morboso y espeluznante. Comenzó lo que posteriormente se bautizó como "el show del horror": la presencia permanente, en el espacio público, de las víctimas y el daño que les habían infligido sus victimarios. En ese marco, además, la actuación pública de los distintos organismos de derechos humanos y el levantamiento de la veda política permitieron la creciente circulación de información, más allá del sensacionalismo de la prensa. Las denuncias y "revelaciones" fueron inscriptas en plataformas y programas sectoriales y partidarios, transformándose en un elemento clave de la transición democrática.

De este modo, con un énfasis en la descripción del horror y en la historia de las víctimas, el "qué" y el "cómo" comenzaron a cobrar forma y contenido. Pero el "porqué" se revela complejo aún hoy, treinta años después. Las dimensiones de los crímenes expuestos, el carácter masivo que comenzaban a revelar, generaron un sentimiento de repudio e indignación que caló hondo en amplios sectores sociales. El rechazo moral a estos crímenes (cometidos, conviene no perderlo de vista, por un régimen que había contado con un amplio consenso al tomar el poder) llevó a que se cambiaran las miradas sobre el gobierno militar y sus acciones: la "lucha contra la subversión" comenzó a llamarse "represión ilegal" y "violaciones a los derechos humanos". Sus víctimas pasaron a ser, en gran medida, de "peligrosos guerrilleros" a "inocentes", en un proceso que reducía las posibilidades de analizar políticamente la época que se buscaba dejar atrás, tanto como agrandaba las proporciones del "mal" que había "caído" sobre la Argentina. Esta operación simbólica se logró fundamentalmente mediante el procedimiento de "inocentar" a las víctimas: se trataba de realzar las características criminales del Estado argentino, y aunque la simple exposición de los delitos hubiera sido suficiente, el efecto era mayor frente a hechos particularmente aberrantes. Este esquema fue visible durante el Juicio a las Juntas (1985), donde por ejemplo fiscales y jueces evitaron cuidadosamente indagar en torno al pasado político de los testigos, víctimas del terrorismo de Estado precisamente por esa condición.

Esto transformó el relato de la dictadura en un catálogo de aberraciones sin una explicación histórica o política. Amplios sectores sociales pasaron del estupor a una condena en términos éticos, que - aunque deseable - obturaba la revisión de la historia y la política argentinas, y por lo tanto, la asignación de las responsabilidades de la tragedia. 


\section{Las víctimas}

En el escenario público argentino las voces de las víctimas han desempeñado y desempeñan un papel central desde principios de la década del ochenta a la actualidad. Fueron los testimonios de los afectados por el terrorismo de Estado los que nos llevaron a visitar el horror de los campos clandestinos de concentración. Para amplios sectores sociales, las historias y denuncias de los padres de desaparecidos, y en menor grado sobrevivientes fueron las primeras voces que relataron la ausencia y las tremendas historias vinculadas a la represión ilegal. De este modo, la experiencia argentina aparece estrechamente vinculada a la demanda de justicia fuertemente concentrada en actores sociales que asumen el compromiso de hacer públicas sus historias. En este proceso, en mayor o menor grado el deber de memoria de quienes sobrevivieron a situaciones extremas es delegado en quienes los escuchan. Se genera una relación compleja y ambigua con el pasado, encarnado en las voces de algunos de sus protagonistas. Así evoca su protagonismo una sobreviviente de la Escuela de Mecánica de la Armada, uno de los mayores centros clandestinos de detención argentinos:

Yo creo que en Argentina, ya desde el periodo de la dictadura, cobra importancia el rol de los sobrevivientes. En los centros clandestinos la posibilidad de contar, de que alguien, aunque sea uno, se salvara para denunciar, fue uno de los ejes de la resistencia y de la misma posibilidad de sobrevivir. Esa fue una especie de obsesión para los prisioneros. En mi caso, que estuve en la ESMA (donde se dio una experiencia bastante particular), el tema de que alguno de nosotros lograra salir y pudiera contar lo que allí ocurría fue más allá de esta obsesión propia de la situación de los centros clandestinos; también desempeñó un papel importante en el compromiso un tanto difuso - pero compromiso al fin - de quienes integraban el grupo que finalmente salió en libertad, al cual yo pertenecía. Uno de los puntos era el compromiso de dar testimonio. Y de algún modo, nuestra primera acción en términos de memoria se dio cuando, aun en la época de la dictadura, algunos salimos en libertad al exterior y comenzamos a dar a conocer lo que sucedía y se empezó a hacer llegar a algunos organismos internacionales - de modo disperso, a veces públicamente, otras 
en forma confidencial - testimonios y denuncias de lo que ocurría en los centros clandestinos de Argentina. Estas voces estuvieron entre las primeras que contaban qué estaba pasando en ese mundo que, hasta que uno estaba ahí adentro, era una incógnita total. Esas declaraciones de diverso tipo, en general daban información sobre quiénes estaban a cargo de la represión, cómo estaba organizada, los nombres de los prisioneros que podíamos recordar, entre otros datos [...]

Evidentemente, había muchas cuestiones que hacían muy difícil explicar cuál era el mundo de los centros clandestinos, todo lo difuso que había ahí. La gente nos pedía héroes o traidores, blanco o negro, cosas que no existían de esa manera, o, por lo menos, no existieron en mi experiencia. Pero, además, decir que no existían también era medio sospechoso. La sospecha de por qué estábamos vivos y qué habíamos hecho para estarlo, era una especie de "por algo será". En ese sentido, esa etapa fue muy difícil (Pastoriza, 2004).

La cita, aunque extensa, muestra la trama compleja de situaciones que genera la circulación de testimonios. Se trata de ejercicios de memoria que ponen en diálogo lo privado y lo público, que responden a necesidades existenciales de quienes los brindan pero también de quienes los reciben. Sus consecuencias, por lo tanto, también deben ser buscadas y pensadas en ambos niveles. La pregunta acerca de para qué y para quiénes se testimonia es central. Deben respondérsela los testigos, los que abren experiencias personales a la confrontación con otras personas. Pero son preguntas que también deben hacerse quienes escuchan y quienes preguntan. ¿Qué sucede cuando el deber de memoria alimentado en las mazmorras del horror, el compromiso con los ausentes, la voluntad de denuncia sostenida a solas mientras se aguarda el retorno del ser querido, ven la luz pública, y se transforman a la vez en la memoria dominante sobre un suceso?

\section{La teoría de los dos demonios}

Durante la década del ochenta, los relatos de la represión contribuyeron, asimismo, a consolidar una narrativa histórica acerca del importante proceso 
de movilización social y la violencia política previos al golpe militar: la violencia guerrillera anterior al Proceso de Reorganización Nacional fue equiparada al terrorismo de Estado en el marco de una condena general a la violencia. Según esta lectura, la sociedad argentina había presenciado como espectadora pasiva el enfrentamiento entre dos fuerzas igualmente violentas en sus procedimientos y repudiables por una sociedad democrática.

El modelo emblemático de esta concepción es el famoso prólogo del Nunca Más, el Informe de la Comisión Nacional sobre la Desaparición de Personas (CONADEP), que afirmaba que "durante la década del 70 la Argentina fue convulsionada por un terror que provenía tanto desde la extrema derecha como desde la extrema izquierda" (CONADEP, 1997, p. 7).

Esta explicación, conocida como "teoría de los dos demonios", cumplió dos finalidades claves para el desarrollo de la transición a la democracia argentina: ofreció la posibilidad de identificar, por un lado, responsables de la tragedia (las organizaciones guerrilleras y las Fuerzas Armadas) y, por el otro, la vía para plantear la democracia como un sistema nuevo en un terreno ajeno a ambas prácticas. De este modo, el sistema democrático no era el heredero de un proceso histórico de una violencia inaudita, sino el camino para realizar un cambio fundacional. Así, puesto que no se intentaba una explicación procesual sobre las situaciones de violencia y autoritarismo en los años previos, las raíces del mal parecían haber nacido abruptamente el día del golpe de Estado - el 24 de marzo de 1976.

$\mathrm{Al}$ señalar claramente dos agentes como los principales responsables de la violencia, la teoría de los dos demonios, por otra parte, se transformó en un mecanismo exculpatorio para amplios sectores sociales que habían apoyado de un modo u otro los golpes de Estado y que ahora veían con horror las consecuencias de esa acción. De un modo simple puede decirse que esa "teoría" fue eficaz porque ofrecía una explicación para un pasado presentado como aberrante y disruptivo de un devenir histórico más "civilizado", porque identificaba responsables (ajenos a la mayoría de la sociedad) y de este modo permitía el inicio de la etapa democrática por aquellos individuos incluidos dentro del sector de "inocentes" y "ajenos" a la violencia. Fue en este contexto que se desarrolló la política de derechos humanos del primer gobierno democrático. 


\section{Las víctimas inocentes}

Un complemento necesario en esta visión condenatoria fue la construcción de una imagen de las víctimas libres de todo aquello que pudiera asociarlas a la violencia y "culpabilizarlas" desde la lógica represiva. Por oposición, la figura de las Fuerzas Armadas como la encarnación del Mal se agigantaba y afianzaba. En este proceso los jóvenes ocuparon un papel central.

Durante los años de la dictadura, el movimiento de derechos humanos, desde una posición minoritaria y frente a un Estado represivo, debió enfrentar una propaganda dictatorial que tendió a concentrar en los jóvenes tanto los extremos de la perversidad de la subversión como la propensión a caer bajo la influencia de ideologías extremas. En consecuencia, los reclamos de los familiares acerca del paradero de sus hijos evitaron cuidadosamente las causas que habían originado su desaparición. En un contexto de escasísimas respuestas a las demandas de paradero, era por lo menos insensato colocarse, como reclamantes, en el lugar de los estigmatizados por el discurso dictatorial. Con el retorno de la democracia, la voluntad de señalar la magnitud de los crímenes cometidos por la dictadura llevó a enfatizar los rasgos de "inocencia" de las víctimas y una de las claves en este proceso fue la imagen de las víctimas adolescentes de la dictadura militar.

Un ejemplo emblemático de este proceso es la figura de los adolescentes. Este sector de las víctimas comenzó a cobrar peso en un sentido inverso al de la propaganda militar, manteniendo como característica central su inmadurez y propensión a la manipulación, lo que, a la vez, los convertía en víctimas inocentes de la dictadura. Se trataba de personas incompletas en su desarrollo, alimentadas por fuertes ideales pero carentes de "elementos políticos y culturales" como para resolverlos; estas características refuerzan la imposibilidad de explicar los crímenes que padecieron. Frente al realce de sus cualidades morales, la figura de las víctimas perdió sus aristas políticas. El emergente de estos procesos sociales de apropiación fue la imagen de la víctima inocente, joven, en un arrastre de la respuesta a la propaganda dictatorial y acudiendo a la necesidad de reforzar los elementos de condena al gobierno militar.

El modelo simbólico de este mecanismo de construcción de memorias de la dictadura es el episodio represivo conocido como La noche de los 
lápices. Entre el 15 y el 21 de septiembre de 1976, hubo en la ciudad de La Plata, provincia de Buenos Aires, un gran operativo represivo contra el movimiento estudiantil, muchos de cuyos integrantes participaban también en los frentes de masas de las organizaciones guerrilleras. En esa semana fueron secuestrados varios estudiantes secundarios. Los adolescentes habían participado en las movilizaciones por el boleto estudiantil secundario de la primavera de 1975, que había logrado una tarifa preferencial para los estudiantes. Este beneficio había sido removido por el gobierno militar de la provincia poco después del golpe de marzo, y las autoridades estaban en conocimiento de que los grupos estudiantiles preparaban demostraciones al respecto, en el contexto de otras acciones de denuncia contra la dictadura militar. Durante su cautiverio, los jóvenes fueron sometidos a torturas y vejámenes en distintos centros clandestinos: el Pozo de Arana, el Pozo de Banfield y la Brigada de Investigaciones de Quilmes. Seis de ellos continúan desaparecidos. Sólo Pablo Díaz, Emilce Moler y Patricia Miranda sobrevivieron. Pero fue a través de Díaz, en un primer momento, que el relato de este episodio de la represión tomó estado público durante la restauración democrática.

En el contexto de transición a la democracia que describimos fue que se conoció la historia de La noche de los lápices. Este caso trasladó las imágenes de la represión al espacio educativo y a los adolescentes, y funcionó como una vía para que en las escuelas se hablara del tema de la represión. Más aún, se transformó en un emblema de la represión, debido a la confluencia de varios elementos: el clima de los primeros años de la transición a la democracia, un libro, una película, y, sobre todo la presencia de un testigo: Pablo Díaz, sobreviviente de la matanza.

Hasta el momento del Juicio a las Juntas Militares, en 1985, el episodio de la Noche de los lápices era muy poco conocido. Pero con la declaración de Pablo Díaz como testigo, el 9 de mayo de ese año, el caso tomó estado público. La figura de los jóvenes víctimas de la represión, conocida en uno de los primeros testimonios vertidos durante el Juicio, concentraba varios elementos que influyeron en su difusión: adolescentes frente a adultos que los reprimen (aún estaban estudiando) por un reclamo "apolítico", de carácter gremial (el boleto secundario), que pocos considerarían injusto o inadecuado.

Por distintos motivos, otras sobrevivientes no declararon durante el Juicio. De este modo, Pablo Díaz se convirtió en la encarnación de todos 
estos emblemas. Era un sobreviviente al terrorismo estatal, víctima de la represión, y también uno de aquellos jóvenes proclives a ser "captados" por la guerrilla de la propaganda dictatorial. Por otra parte, la historia del boleto permitía asociar el activismo de las víctimas con un reclamo "justo", lo que sería clave a la hora de la circulación de la historia. En esta coyuntura, Pablo Díaz asumió un rol decisivo como portavoz e impulsor de esa memoria. Al igual que muchos sobrevivientes, sentía frente a sus compañeros desaparecidos el deber de testimoniar, y eso lo transformó en un emblema viviente del terrorismo de Estado. Después de su declaración en el Juicio a las Juntas, comenzó para él una febril actividad de denuncia y difusión. El relato conformado en los años iniciales de la transición, después de la declaración judicial de Pablo Díaz, se vio reforzado por dos vehículos culturales de primera magnitud: un libro, editado por primera vez en junio de 1986, y una película, estrenada el mismo año.

\section{El retorno de los militantes}

Este proceso de consolidación de la experiencia acerca del terror estatal comenzó a ser enriquecido a mediados de los años noventa. Otros supervivencias y trayectorias comenzaron a agregarse a la memoria del horror: aquellas de los integrantes de las organizaciones revolucionarias, que reivindicaban su experiencia en los años previos al golpe, de intensa movilización política y social. ¿Fue el proceso de denuncias de finales de los setenta y principios de los ochenta la base necesaria para este resurgimiento de las memorias políticas del pasado? Sin duda. Pero es cierto que la reivindicación de la experiencia política traía numerosas disrupciones a la simplificación conceptual que la teoría de los demonios había traído aparejada: ¿era posible, por ejemplo, instalar la discusión de que una víctima del terror estatal podía, a su vez, haber sido victimaria de un jefe de personal, en una fábrica, como parte de una "lucha contra el capitalismo" para "instaurar el socialismo nacional"? ¿Cómo hacerlo sin que esto fuera leído como la aceptación de los argumentos de los militares, que reivindicaban a su vez su "guerra contra la subversión"? ¿Cómo eludir esta trampa ideológica?

Otro espacio de confrontación es el generacional: los militantes pertenecen a la misma franja etaria que los desaparecidos, son compañeros, 
esposos, hermanos de los hijos de las madres y abuelas que salieron a reclamar por la desaparición de sus vástagos desde mediados de la década del setenta, con el repertorio simbólico que describimos anteriormente. La legitimidad pública de los organismos de derechos humanos (o de "afectados directos") pasaba fundamentalmente por una cuestión cosanguínea y vinculada al vínculo familiar; desde mediados del noventa, un nuevo lazo, el político, es reivindicado. Documentales, obras testimoniales, analíticas o de ficción, constituyen un boom editorial y periodístico notable, que se refuerza cada aniversario del golpe. Demás está decir que el relato de las vidas militantes contradice fuertemente la imagen de las víctimas de la dictadura construidas en la década del ochenta.

$\mathrm{Al}$ respecto, los debates y los sucesos que a partir de marzo de 2004 se vienen sucediendo en relación con las interpretaciones acerca de la dictadura militar son paradigmáticos. Ese año, el día del aniversario del golpe del 24 de marzo, el presidente Néstor Kirchner pidió perdón en nombre del Estado desde la ESMA, ${ }^{1}$ y se reivindicó como parte de la generación perseguida por la represión. Días antes, había ingresado a ese predio acompañado por ex detenidos - desaparecidos sobrevivientes de dicho campo clandestino, junto a quienes lo recorrió. Este año, en ocasión del trigésimo aniversario del golpe, la decisión estatal de transformarlo en feriado nacional reavivó la polémica.

Las repercusiones de estos gestos recalentaron las memorias acerca de la violencia política y la represión, reeditando en muchos casos debates sostenidos casi en los mismos términos que dos o tres décadas atrás. En el campo intelectual, a partir de un artículo publicado en la revista cordobesa La intemperie numerosos intelectuales vienen desarrollando un debate que revisa, entre otras cosas, la responsabilidad de los individuos en relación con decisiones que implican el asesinato de otras personas con fines políticos, o la idea misma de revolución. La decisión gubernamental de reeditar el informe Nunca Más con un nuevo prólogo (que revisa la "teoría de los dos demonios") ha despertado también reacciones por parte

1 La ESMA, Escuela de Mecánica de la Armada, es un inmenso edificio de la marina que durante la dictadura militar funcionó como centro clandestino de detención. Se calcula que por allí pasaron unos cinco mil secuestrados, la mayoría de los cuales permanece desaparecida. Actualmente, el predio de la ESMA, de casi 17 hectáreas, constituye el Espacio para la Memoria, la verdad y la Justicia, y allí se están estableciendo diversas instituciones que desarrollarán iniciativas culturales, académicas y educativas. 
de quienes consideran a este un texto intangible y al gobierno de hacer un uso particular del pasado reciente.

Pero este proceso de reivindicación de la experiencia política puede traducirse en el relato hagiográfico o excesivamente laudatorio tanto acerca de las víctimas de la represión como sobre la militancia revolucionaria. En su reciente libro Tiempo pasado. Cultura de la memoria y giro subjetivo. Una discusión, la crítica literaria Beatriz Sarlo analiza el impacto de los testimonios en la construcción pública de relatos sobre el pasado reciente para el caso argentino. Retomando diferencias tajantes entre la historia y la memoria, revaloriza el lugar de la crítica histórica en la construcción del pasado y se propone reflexionar acerca de las voces de las víctimas y el lugar que tuvieron en el espacio público desde el retorno de la democracia, como una forma de alertar acerca de las consecuencias que su predominancia, a su juicio, tuvo a la hora de matrizar los relatos acerca de la dictadura y la guerrilla:"Este libro se ocupa del pasado y la memoria de las últimas décadas. Reacciona no frente a los usos jurídicos y morales del testimonio, sino frente a sus otros usos públicos. Analiza la transformación del testimonio en un icono de la verdad o en un recurso más importante para la reconstrucción del pasado; discute la primera persona como forma privilegiada frente a discursos de los que la primera persona está ausente o desplazada" (Sarlo, 2005, p. 23).

¿Qué esta cuestionando la ensayista? No sólo una forma, una matriz narrativa para aproximarse al pasado, sino también una legitimidad construida en base a la experiencia para hablar políticamente acerca de la Historia

\section{Tensiones}

Es en este contexto y sometido a estas tensiones que los historiadores (entre otros) realizan su trabajo. ¿Es posible una aproximación crítica al pasado, por ejemplo, sin adherir a la tajante división entre historia y memoria planteada por Beatriz Sarlo? A modo de escollos a lo largo de la navegación, enumeraremos algunos de los elementos que no facilitan dar una respuesta definitiva al problema: 


\section{Presencias y ausencias}

Una primera observación es que los relatos acerca del pasado encarnados en actores tan definidos permiten señalar toda una seria de ausencias y sobrerrepresentaciones que deberían permitir redactar una agenda de investigación. La construcción de la figura del desaparecido en los ochenta (directamente vinculada tanto a la propaganda militar que debía ser combatida como a quienes tuvieron recursos simbólicos para hacerlo), por ejemplo, consolidó la imagen del joven de clase media, con estudios, víctima de la represión. El grueso de los relatos testimoniales sobre la militancia que circulan desde hace un tiempo, a su vez, provienen de actores de esta extracción social, que a la vez canalizaron su participación política en formas y agrupaciones concretas. Esto hace que, por caso, carezcamos prácticamente, aún, de estudios acerca de la experiencia política y la represión al movimiento obrero en la década del setenta, de sus representaciones acerca de su lucha política y la violencia que padecieron.

Carecemos prácticamente de trabajos en torno a la vida cotidiana durante la dictadura de la "zona gris", aquellos hombres y mujeres que transcurrieron aquellos años sin ser afectados en forma directa por la represión. No hemos analizado, casi, la forma en la que los reivindicadores de la dictadura relatan aquellos años, ni sus experiencias.

\section{Jerarquías del dolor}

Algunas víctimas de la dictadura militar han tenido más posibilidad que otras de hacer circular sus voces, y esto se traduce en cuestiones analíticas a resolver por una agenda de investigación. Los sobrevivientes de la guerra de Malvinas, los deudos de los muertos en ese conflicto, por ejemplo, sin duda son un ejemplo de ello. Asociados al gobierno militar por la reivindicación que hacen de la experiencia bélica (constitutiva de su identidad tanto como la militancia o la pérdida para los integrantes de organismos de derechos humanos o ex activistas políticos) son aún los grandes ausentes del debate público sobre el pasado. Pero existen otros: los sobrevivientes de los campos de concentración (situación que se va revirtiendo hoy), los exiliados o, sencillamente, quienes transcurrieron esos años en el país, más o menos ajenos, consciente o inconscientemente al margen de lo que sucedió. 


\section{Jerarquías del compromiso}

En un primer momento, buena parte de las iniciativas acerca del pasado provinieron de los afectados directos y tuvieron la forma de reclamos de justicia y reparación. A partir de esta incontrastable realidad histórica, en el sentido común de muchos de estos actores funciona una escala de valores que traza una serie de círculos concéntricos a partir del hecho traumático de la pérdida en el que sus conciudadanos (entre ellos los investigadores asociados a su problemática) son colocados: en primer lugar, el compromiso viene dado por la cercanía con el dolor, o por la sangre.

Desde el punto de vista analítico, esto no deja de ser un problema. Al discutir la conformación de un archivo, por ejemplo, no es de extrañar que este tipo de criterios predominen por sobre los más "fríos" de quien encara una tarea de construcción y preservación sin otra motivación más que el compromiso con el tema y realizar del modo más completo y riguroso su tarea. En determinadas situaciones y discusiones esta barrera es in franqueable.

\section{La propiedad sobre el pasado}

El punto anterior se relaciona con la autoridad para hablar sobre el pasado, con el traslado de ese argumento tan común en las discusiones consistentes en el "vos no la viviste", pero fortalecido en este caso por la legitimidad devenida de la pérdida. Si bien en el espacio público está visión es contradicha o confrontada, no es para nada pequeña a la hora de alimentar los argumentos que sostienen una discusión, por ejemplo, acerca de la conformación de un archivo, o en una mesa de trabajo que se plantee, por caso, la redacción del guión de un museo sobre el terrorismo de estado. Aquí se trata de compatibilizar la voluntad del investigador de mostrar la complejidad y diversidad de las aproximaciones al pasado con aquellas visiones monolíticas construidas a partir de la propia experiencia. Lo que es más grave, eludir esta discusión deja latente el peligro de la fijación en la herida producida por la represión, por la imposibilidad de pensar más allá del dolor, confinándonos a revolvernos dentro de él, como si se tratara de una prisión. 


\section{La hagiografía}

Hay una tendencia muy fuerte en las producciones recientes a la conformación de un relato reivindicatorio acrítico de la experiencia revolucionaria. Como suele suceder en una situación de crisis y decadencia moral, se tiende a mirar hacia el pasado desde la idealización. Esta tendencia se ve reforzada porque en ese pasado vive la juventud perdida, junto con los idos, los ausentes más queridos. Esta tendencia nubla, por ejemplo, las posibilidades de una discusión histórica - y la consecuente revisión política - que permitiría pensar, entre otras cosas, el porqué del fracaso de las izquierdas. O cuánto del disciplinamiento autoritario de los setenta permanece en nuestro presente.

Este tipo de relatos reivindicatorios, por otra parte, refuerzan las visiones conspirativas que sectores reaccionarios construyen en torno al pasado, pues caracterizan cualquier iniciativa pública de memoria como una revancha y no como un esfuerzo de aproximación a la verdad (Lorenz, 2007).

\section{Desafíos}

La cita de George Orwell que abre este texto apunta al corazón de la cuestión sobre la que considero importante reflexionar: el sentido, el para qué de las iniciativas de memoria. Fundamentalmente, en este caso, el trabajo con testimonios orales, la circulación de las voces de los protagonistas y su preservación: Volvió a preguntarse para quién escribia el Diario. ¿Para el pasado, para el futuro, para una época imaginaria? Winston Smith, el protagonista de 1984 que realizaba su gran acto de resistencia al iniciar las páginas de un diario escrito con formas y sobre materiales de otra época, reflexionaba sobre su pasado desde un presente agobiante, pero pensando en quienes iban a leerlo. Su voluntad era trascender, superar la asfixia de ese presente pero, también, el paso del tiempo. Pero la fuga, no obstante, puede ser hacia delante, hacia el futuro, o el repliegue a un pasado visualizado como idílico.

La socióloga Pilar Calveiro, en su libro Política y/ o violencia advierte en sus párrafos iniciales que "la repetición puntual de un mismo relato, sin variación, a lo largo de los años, puede representar no el triunfo de la memoria, sino su derrota. Por una parte, porque toda repetición 'seca' el 
relato y los oídos que lo escuchan; por otra, porque la memoria es un acto de recreación del pasado desde la realidad del presente y el proyecto del futuro" (Calveiro, 2005, p. 11). Como apertura de un libro que se propone reflexionar acerca del fenómeno de la violencia política, y que no elude la primera persona (Calveiro es ella misma una sobreviviente) no es una enunciación menor. Traslademos, por ejemplo, esta reflexión al espacio educativo, donde se dirigen muchas de las iniciativas públicas de memoria: el trabajo docente en relación con el pasado, al igual que cualquier ejercicio de memoria humano se encuentra amenazado por esta posibilidad: agotar la vida que busca reproducir en el proceso de transmisión, cerrar las vías para la transmisión de la experiencia social. Quien evoca con vistas al futuro puede, aún buscando lo contrario, desempolvar esqueletos que no encontrarán oídos para sus palabras, incomprensibles para los "nuevos" que los escuchan. Sin embargo, si la evocación viene bajo la forma de un deber de memoria, los alumnos deberán cargar con ellos, sin posibilidad de prestar atención a su presente y al futuro que aún aguarda ser imaginado.

Se trata, para los protagonistas directos, de un acto de extrema generosidad: allanarse al proceso de olvido necesario a cualquier proceso de construcción de una memoria social: "Desde el punto de vista político, no podemos seguir combatiendo a un enemigo ya vencido y permanecer ciegos ante lo que se desarrolla ante nuestros ojos. La historia continúa. El mal ha adoptado nuevas formas. No es lícito que, en nombre de la memoria - aún de la más legítima -, descuidemos las nuevas encarnaciones del mal ni encubramos los peligros del presente. Los muertos no deben impedir a los vivos seguir viviendo" (Schnapper, 2002, p. 79).

Si bien se puee pensar como exagerada esta idea de "lucha contra el mal", lo que no debe perderse de vista de la cita es la advertencia acerca de cómo muchas veces nuestro trabajo, aún dirigido por las mejores intenciones, puede perpetuar la obra del terror. La figura fantasmática del desaparecido sobrevuela la imposibilidad de pensar políticamente el pasado desde un presente que requiere respuestas.

Si nosotros como historiadores, tenemos en cuenta estas advertencias, las consecuencias sobre nuestro trabajo deberían traducirse en la pregunta acerca de la politicidad del mismo, del para qué. Susan Sontag escribió que "sin política, las fotografías del matadero de la historia simplemente se vivirán, con toda probabilidad, como irreales o como golpes emocionales 
desmoralizadores" (Sontag, 2003, p. 36). Irreales por pertenecer a otra época (y dicha irrealidad se exacerba si proyectamos la permanencia de tales imágenes (testimonios) décadas o siglos a futuro. Golpes emocionales desmoralizadores tanto en el sentido de la magnitud de la pérdida, del dolor paralizante, o también por la nostalgia desmesurada frente a épocas idealizadas como definitivas y vitales.

En la interacción con los actores del pasado que estudiamos, la respuesta a esta pregunta política se traduce en situaciones incómodas y tensiones que tienen tanto de metodológicas como de vitales. La voluntad de reparar las ausencias temáticas y atemperar las sobrerrepresentaciones en un archivo, por ejemplo, choca con lo que es la necesidad vital de quienes son parte de él, de quienes contribuyen a organizarlo o a dar su testimonio, en muchos casos afectos o personas con quienes simpatizamos.

La cuestión de las legitimidades no es menor. Hace pocos años, mi trabajo como historiador me llevó a encontrar en mi familia el mismo silencio que estudiaba en los demás: un desaparecido, primo hermano de mi mamá. Al contarlo en el archivo audiovisual en el que ese momento trabajaba, la respuesta de mi coordinadora, una sobreviviente ella misma fue abrazarme y decirme que "ahora ya era uno de ellos". ¿Qué significaba eso? ¿Qué todo mi trabajo anterior, mi compromiso ético con el tema, mi voluntad política de difusión y reparación no habían sido suficientes hasta entonces? ¿Qué plus le daría a mis opiniones esa situación a partir de entonces y, a la inversa, en cuanto habían desvalorizado o por lo menos relativizado mis intervenciones profesionales hasta ese momento?

Esta situación, que fue altamente conflictiva para mí (y finalmente determinó mi desvinculación del archivo) revela un elemento central, que hace también al lugar que los investigadores imaginamos para nosotros mismos dentro de la sociedad en la que trabajamos. Si nuestra voluntad es la de incidir políticamente con nuestro trabajo (en mayor o menor grado), debemos entender aceptar que existen distintas formas de legitimar los relatos sobre el pasado, y que en consecuencia nuestras voces, por más autorizadas que estén interpares, son una más, y ni siquiera la más eficaz o valorizada, en el debate público. Esto no es necesariamente ni bueno ni malo, es una realidad de nuestro trabajo, y en todo caso tener presentes y estudiadas estas limitaciones nos ayudará a reflexionar mejor sobre nuestras prácticas, desde el punto de vista de cómo pueden aportar más eficazmente a la discusión pública que buscamos dar. En todo caso, se 
trata de elegir al caudal de qué río, con el rigor de nuestras herramientas profesionales, queremos contribuir: una elección temática, una aproximación metodológica, un modo de intervención, dicen mucho acerca de las preguntas políticas que nos hacemos.

Al trabajar sobre el pasado reciente con testimonios, muchos de los dilemas que enfrentamos son sencillamente insalvables. Es por eso que la pregunta del para qué es central: porque constituye un reaseguro tanto contra el desaliento como contra la euforia, un antídoto contra el relativismo o la ceguera ideológica. El contenido ético de nuestro trabajo, al referirnos al pasado reciente particularmente, pero hacia cualquier pasado en general, está en el acto mismo de preguntar. Nuevamente Susan Sontag, aunque refiriéndose a las imágenes de guerra, sintetiza esta percepción:

La persona que está perennemente sorprendida por la existencia de la depravación, que se muestra desilusionada (incluso incrédula) cuando se le presentan pruebas de lo que unos seres humanos son capaces de infligir a otros - en el sentido de crueldades horripilantes y directas- no ha alcanzado la madurez moral o psicológica. A partir de determinada edad nadie tiene derecho a semejante ingenuidad y superficialidad, a este grado de ignorancia o amnesia [...] Debemos permitir que las imágenes atroces nos persigan [...] Las imágenes dicen: Esto es lo que los seres humanos se atreven a hacer, y quizá se ofrezcan a hacer, con entusiasmo, convencidos de que están en lo justo. No olvides. Esto no es exactamente lo mismo que pedirle a la gente que recuerde un ataque de maldad singularmente monstruoso ("Nunca olvides"). Quizá se le atribuye demasiado valor a la memoria y no el suficiente a la reflexión. Recordar es una acción ética, tiene un valor ético en y por sí mismo" (Sontag, 2005, p. 133-4).

Se trata, en consecuencia, de promover una política del recuerdo "no ingenuo", entendiendo por este aquel que se hace preguntas políticas sobre el pasado que estudia. Los historiadores y otros investigadores sociales no son ilustradores, aportan evidencia para una relación crítica con la sociedad. En este lugar clave de la transmisión, la reflexión, y la construcción de sociedades más justas, se ubican las voces recogidas, preservadas, difundidas y, también, silenciadas. 


\section{Bibliografía citada}

CALVEIRO, Pilar. Politica y/ o violencia: una aproximación a la guerrilla de los años 70. Buenos Aires: Norma, 2005.

CONADEP, Comisión Nacional sobre la Desaparición de Personas. Nunca Más. $3^{a}$ ed. Buenos Aires: Eudeba, 1997.

LORENZ, Federico. Recuerden argentinos. Por una revisión de la Vulgata procesista. In: Combates por la Memoria. Huellas de la dictadura en la Historia. Buenos Aires: Capital Intelectual, 2007.

PASTORIZA, Lila. Una mirada que se abre al futuro. Puentes, v. 5, n. 13, La Plata, Comisión Provincial por la Memoria, 2004.

SARLO, Beatriz Tiempo pasado, cultura de la memoria y giro subjetivo: una discusión, Buenos Aires, Siglo XXI, 2005.

SCHNAPPER, Dominique. La memoria en la política. In: AA.VV., ¿Por qué recordar? Barcelona: Gránica, 2002.

SONTAG, Susan. Ante el dolor de los demás. Buenos Aires: Alfaguara, 2003 Sobre la fotografía. Buenos Aires: Alfaguara, 2005.

Resumen: Desde mediados de la década del noventa, el espacio público argentino es escenario de una creciente circulación de testimonios acerca de los años de la dictadura militar (1976-1983). Este fenómeno no es nuevo, pero una notable diferencia entre estes trabajos y aquellas primeras versiones del exterminio radica en que actualmente la figura de los militantes políticos vuelve a cobrar relevancia, desplazando a la de las víctimas, característica de la salida de la dictadura. Trés décadas después de la instauración del golpe militar, resulta importante reflexionar acerca de los condicionamientos que este proceso de memoria imprime al trabajo de los historiadores que utilizan fuentes orales y a quienes se aproximan a ese pasado en busca de (algunas) respuestas.

Palabras-clave: memoria política; testimonio; Argentina; terrorismo de Estado.

\section{Challenges of the work with testimonies in Argentina}

Abstract: Since the mid 1990's, the Argentinean public space has been the stage for a growing circulation of testimonies about the years of the military dictatorship (1976-1983), materialized as the publication of testimonial books, or initiatives for the preservation, recovery or reconstruction of the history from those years. This phenomenon is not new, but there is a noticeable difference between contemporary works and the first versions of the extermination: currently the image of political militants is once again relevant, replacing that of the victims, which characterized the end of the dictatorship. Three decades after the military coup, it is important to reflect on the conditions that this memory process imposes on the work of historians who use oral sources, in particular, and more extensively, on those who get in touch with this past in search for (a few) answers.

Keywords: political memory; testimony; Arrgentine; State terrorism. 